\title{
Relação entre o público e o privado na Educação Básica no Brasil: projetos em disputa
}

\author{
Relationship between the public and private in \\ Basic Education in Brazil: projects in dispute
}

\author{
Vera Maria Vidal Peroni \\ UFRGS/CNPq/FAPERGS
}

\section{RESUMO}

Este texto tem como objetivo trazer alguns elementos para o debate acerca de como as redefinições no papel do Estado reorganizam as fronteiras entre o público e privado, materializando-se das mais diferentes formas na educação básica pública, enfocando, principalmente quem são os sujeitos individuais e coletivos ${ }^{1}$, protagonistas do processo de privatização, tanto do ponto de vista conteúdo das suas propostas e as implicações para o processo de democratização mercadológico, como neoconservador. E ainda, busca trazer elementos sobre qual é o da educação.

\section{PALAVRAS-CHAVE}

Público-privado. Políticas educacionais. Democratização da educação.

\footnotetext{
${ }^{1}$ sujeitos individuais e coletivos na concepção de Thompson, (1981).
} 


\section{ABSTRACT}

This text aims to bring some elements to the debate about how the redefinitions in the role of the State reorganize the boundaries between public and private, materializing in the most different forms in public basic education, focusing mainly on who are the individual subjects and protagonists of the privatization process, both from the market and neoconservative point of view. And yet, it seeks to bring elements about what is the content of its proposals and the implications for the process of democratization of education.

\section{KEYWORDS}

Public-private. Educational policies. Democratization of education. 
0 texto apresenta questões teóricas acerca da presença de sujeitos vinculados ao mercado e ao neoconservadorismo na direção das políticas educativas, apresenta um pequeno debate sobre thinkthanks, que atuam produzindo conhecimento e disseminando suas propostas na sociedade, e mais especificamente na educação, apontando alguns exemplos de como este processo está se materializando no Brasil. E, por último, algumas considerações de como estes processos têm importantes implicações para a construção da democracia no país.

No caso brasileiro, o Estado continua o responsável pelo acesso,sendo que mais de $80 \%$ das matriculas da educação básica na escola pública. No entanto, o "conteúdo" pedagógico e de gestão da escola é cada vez mais determinado por instituições que introduzem a lógica mercantil, com a justificativa de que assim estão contribuindo para a qualidade da escola pública. Nos últimos anos, além do mercado, também o neoconservadorismo tem assumido a pauta educacional.

Iniciamos com o conceito de política educacional.Entendemospolítica educacional como parte constitutiva das mudanças sociais e econômicas em um período particular do capitalismo. Évista aqui como a materialização das mudanças que estão ocorrendo no movimento do real da sociedade, resultado de correlação de forças que ocorrem no Estado e sociedade civil.

Assim que, a relação entre o público e o privado na educação, não se trata apenas de propriedade, mas projetos societários em disputa. Sendo que, tanto no Estado, quanto na sociedade civil existem forças sociais que defendem projetos com interesses vinculados ao mercado ou ao neoconservadorismo. Com profundas implicações para a construção de uma sociedade democrática, pelo importante papel da educação neste processo.Democracia entendida como a materialização de direitos em políticas coletivamente construídas na autocrítica da prática social (Peroni, 2015).

Os processos de privatização do público podem ocorrer via execução e direção, em que o setor privado atua diretamente na oferta da educação, ou quando a atuação do privado ocorre na direção das políticas públicas ou das escolas, sendo que a propriedade permanece pública. Neste sentido, a relação público-privada tem como concepção, não apenas a propriedade, mas os projetos societários em disputa em uma perspectiva de classe.

Entendemos que o diagnóstico do capital de que o Estado culpado pela crise e o mercado deve ser o padrão de padrão de qualidade, está na raiz do avanço da privatização do público. As fronteiras entre o público e o privado têm-se modificado no contexto atual de crise do capitalismo e suas estratégias de superação - neoliberalismo, globalização, reestruturação produtiva e terceira via - redefinem o papel do Estado, principalmente para com as políticas sociais. 0 neoliberalismo e a terceira via, atual socialdemocracia, têm o mesmo diagnóstico de que o culpado pela crise atual é o Estado e o mercado deve ser o parâmetro de qualidade.

Nessa perspectiva, a responsabilidade pela execução e direção das políticas sociais deve ser repassada para a sociedade civil com ou sem fins lucrativos. Assim sendo, tanto o neoliberalismo quanto a terceira via, trazem implicações para o projeto democrático, por quererem esvaziar as instituições públicas das decisões. 0 neoliberalismo, porque acredita que a democracia é responsável pelas demandas sociais que provocam a distribuição de rendas através das políticas públicas, ocasionando o déficit fiscal. A terceira via, por sua vez, por ter o mesmo diagnóstico de crise do Estado, sua proposta de reformá-lo passa por princípios gerenciais, com a lógica da sociedade civil empreendedora que também deve executar as tarefas do Estado (Peroni, 2013).

De alguma forma, as duas teorias propõem o repasse para a sociedade, em alguma medida, da direção e da execução das políticas sociais. E o que permanece com a propriedade estatal também passa a ter a lógica de mercado. É o que Clarke e Newman (2012, p. 358) chamam de estado gerencial: “[...] mesmo onde os serviços públicos não foram totalmente privatizados (e muitos permaneceram no setor público), era exigido que tivessem um desempenho como se estivessem em um mercado competitivo". No livro The ManagerialState, 
Clarke e Newman (2006) apontam para redefinições no papel do Estado, ressaltando que não significa que ele tenha diminuído, mas apenas modificado sua atuação: "O estado tem se retirado em alguns aspectos, seus poderes e aparelhos têm sido expandidos em outros - transferindo responsabilidades, mas simultaneamente criando as capacidades de fiscalização e reforço para garantir que estas responsabilidades estão sendo cumpridas" (CLARKE; NEWMAN, 2006, p. 126).

É importante destacar que a retirada de direitos sociais e trabalhistas e a lógica de mercado na esfera pública não foi simplesmente aceita pela população, foi um longo trabalho de sujeitos individuais e coletivos, organizados ou não em redesnacionais einternacionais. A seguir traremos o papel dos thinktanks neste processo de convencimento.

Camila Rocha (2015), no texto Direitas em rede: thinktanksde direita na América Latina, destaca que o Brasil abriga atualmente 82 organizações classificadas como tal. Isso faz com que sejamos o segundo país da América Latina em número de thinktanks. A autora define thinktanks (TT):

Os thinktanks podem ser definidos de modo mais genérico como instituições permanentes de pesquisa e análise de políticas públicas que atuam a partir da sociedade civil, procurando informar e influenciar tanto instâncias governamentais como a opinião pública no que tange à adoção de determinadas políticas públicas. (...) traduzem resultados de pesquisas especializadas para uma linguagem e um formato que sejam acessíveis para implementadores de políticas públicas e para a população em geral. (ROCHA, 2015, p. 262)

Camila Rocha (2017) destaca, ainda, que desde de o início da sua atuação, a excelência dos TT já se apresentava no sentido de não serem públicos, de serem apolíticos e isentos por estarem vinculados à sociedade civil:

estas organizações não sofreriam interferência ou pressão de grupos de interesse específicos, como ocorreria em agências estatais, governos, universidades ou partidos, o que lhes facultaria a possibilidade de conduzir suas atividades-fim de forma mais "neutra", "científica" e "desinteressada", e por isso mais "confiável” em comparação a outros loci de pesquisa e produção de ideias e políticas públicas, (...) (Rocha, 2017, p. 97)

O formato de atuação inaugurado pela Heritage Foundation marcou o nascimento de um outro tipo de organização nos Estados Unidos: os thinktanks "ativistas" (p. 98).

A Heritage Foundation é tida como um dos thinktankde direitamais influentes dentro e fora dos Estados Unidos. Sua missão é formular e promover políticas públicas conservadoras baseadas na defesa da livre-empresa, do Estado mínimo, da liberdade individual, dos valores tradicionais americanos e da importância de uma forte defesa nacional. Para conseguir influenciar o máximo possível o processo político nesta direção e obter o maior número de vitórias possível na chamada "batalha das ideias", suas estratégias de marketing são direcionadas para um público alvo composto por membros do Congresso, membros de equipes parlamentares, formuladores de políticas públicas no poder executivo, mídia nacional, e comunidades acadêmicas. (grifo nosso) (p. 98)

A autora destaca, ainda que em 1981, com o intuito inicial de fornecer uma espécie de central coordenadora para as organizações de direita que haviam sido criadas até então, foi criada a Atlas Network. Atualmente, é possível dizer que praticamente todos os thinktanks de direita mais importantes ao redor do globo fazem parte da rede constituídapela Atlas. "A atuação da Atlas na América Latina durante os anos 1980 e início da década de 1990 marcou o primeiro momento no histórico de atuação de thinktanks "ativistas" de direita na América Latina. Seja auxiliando na fundação de organizações novas ou incorporando thinktanks criados por elites locais, especialmente por grupos de empresários nacionais e estrangeiros, como é o caso do Brasil com IEE e o Instituto Liberal" (Rocha, 2017, p.272)

MORAES (2016) ressalta que os milionários americanos disseminaram a cultura de mercado, entre outros fatores como parte do esforço de mu- 
dar a imagem do empresariado perante a opinião pública e modelar o ambiente politico, através dos ThinkTanks:

a "novíssima direita" cria emultiplica thinktankse aparatos de mídia (impressa, eletrônica, virtual etc.) para modelar o ambiente politico. De outro lado, operando também como lobbies (pressionando para aprovação de certas politicas ou para o direcionamento das já existentes), eles conseguem esse mesmo objetivo: policies makepolity, diz a sentença. Assim, por exemplo, ocorre com o fato de determinados programas públicos (provisão de saúde, educação etc.) serem financiados pelo público, mas "entregues" através de canais privados: isto os faz, ainda que públicos, reconhecíveis pelo usuário como privados. (MORAES, 2015, p. 240)

Rocha (2017) apresenta a importância dos thinktanks para a propagação das políticas neoliberais no Brasil: "um fator importante que contribuiu nesse sentido foi a propagação de valores neoliberais realizada por empresários, tecnocratas e intelectuais por meio da atuação de thinktanks pró-mercado". (Rocha, 2017, p. 96)

Com os thinktanks, vemos claramente a materialização dos sujeitos individuais e coletivos em relação, com objetivos de classe. Não apenas os sujeitos vinculados ao mercado se organizaram em thinktanks para difundir suas ideias, mas também os neoconservadores.

Harvey (2008) tem nos auxiliado na compreensão da relação entre neoliberalismo e neoconservadorismo. Para o autor, o neoliberalismo provoca o caos social e o neoconservadorismo responde com maior repressão para colocar a casa em ordem.

Em sua preocupação com a ordem, o neoconservadorismo se assemelha a uma mera retirada do véu de autoritarismo com que o neoliberalismo se cobre. Mas também propõe respostas singulares a uma das contradições centrais desse último. Se 'a sociedade não existe, apenas homens e mulheres individuais', como disse de início Thatcher, o caos individual pode vir a se sobrepor à ordem. A anarquia do mercado, da competição sem peias (esperanças, desejos, ansiedades e temores individuais; escolhas de estilo de vida de hábitos e orientações sexuais, formas de auto - expressão e comportamentos com relação aos outros) gera uma situação cada vez mais ingovernável (HARVEY, 2008, p. 92-93)

0 autor ressalta, ainda, que o esvaziamento dos direitos sociais, o aumento do desemprego dos ajustes estruturais e a exacerbação da competitividade e individualismo, provoca caos social e civilizatório e a este risco o neoconservadorismo responde com maior repressão. É o temos vivenciados no Brasil, nos últimos anos.

Conforme MOLL NETO Jr, (2010), em 1955, colunistas da Revista NationalReview, foram protagonistas de uma determinada reinterpretação e reconstrução da ideologia conservadora que ficou conhecida como nova direita ou neoconservadorismo. "A ideologia neoconservadora resgatou e reconstruiu pressupostos de correntes conservadoras que os antecederam, basicamente do velho conservadorismo e do libertarianismo". (p. 65). Conforme o autor, os intelectuais que construíram as bases ideológicas do neoconservadorismo resgataram do tradicionalismo a ênfase moral que, a partir da década de 1960, serviu para atacar moralmente o Estado de Bem Estar Social e os movimentos sociais liberais e do libertarianismo, a ideia de que a sociedade era uma relação contratual entre indivíduos e não um organismo que guarda interesses e objetivos coletivos. Para eles " nada justificava projetos estatais que interferissem na vida das pessoas e limitassem as liberdades, sobretudo a econômica". (MOLL, p. 67).

0 autor ressalta que é somente a partir da crise da década de 1970 que iniciou uma mobilização neoconservadora: ocorreu principalmente através da criação de thinktanks: "Os empresários da nova direita organizaram fundações para reunir capital para apoiar e financiar universidades, pesquisas e centros de estudo (ThinkThanks) a fim de elaborar projetos políticos nacionais". (p. 69)

Nos BPOs (Business PolicyOrganizations BPOs) neoconservadores e ultraneoconservadores havia uma preponderância das elites sulistas, sobretudo do Sunbelt, nos EUA. Dentre as organizações neoconservadores se destacam a Business 
Roundtable, o American Enterprise Institute, a Heritage Foundation e o HooverInstitution.

Com o intuito de demonstrar como estes sujeitos estão presentes na educação, destacamos a pesquisa de Lima (2017) que demostra as relações entre diversos sujeitos, inclusive a Atlas Network, com o Escola sem Partido (ESP), movimento que expressa bem a censura, e a correlação de forças da direita, no sentido de barrar os primeiros passos que estávamos dando em direitos sociais materializados em políticas de diversidade, como parte da construção da democracia em nosso país:

Surgido em 2004, o Projeto Escola Sem Partido (ESP) foi idealizado pelo advogado Miguel Nagib; ao longo dos últimos anos, contou com a ativa colaboração de dois militantes de direita, os irmãos deputados Flávio e Carlos Bolsonaro. A partir de 2014, o ESP passou a influenciar projetos de lei (PL) em âmbito municipal, estadual e federal

Destacamos que o Projeto de Lei 246/19 apresentado pela Deputada Bia Kicis, em tramitação no Congresso Nacional em abril 2019, acrescenta questões pendentes no anterior, como a possibilidade de gravar aulas e sanções prevista aos professores.

O Escola sem Partido expressa bem a relação entre neoliberalismo e neoconservadorismo, já que vários institutos, que apresentam uma pauta voltada ao mercado, financiaram e apoiaram a censura e o neoconservadorismo na educação brasileira.

A questão central foi a censura e o preconceito ter entrado na pauta da sociedade, com naturalidade. 0 projeto consegue adesão de parte da sociedade, que quer barrar principalmente as questões vinculadas às políticas de diversidade, que conforme Rossi (2016), estavam apenas entrando na pauta das políticas educacionais. para Rossi (2016)

Discutir as questões que permeiam a diversidade na escola, na direção devalorizá-las, é fundamental. Acredito que, se lutamos por uma educação pública e dequalidade para todas/os, essas questões devem perpassar o currículo da escola, oPPP, a gestão. Neste momento histórico, não se pode falar de qualidade daeducação sem que se tenha como pressuposto um ensino bási-

FIGURA 1 - Sujeitos do ESP

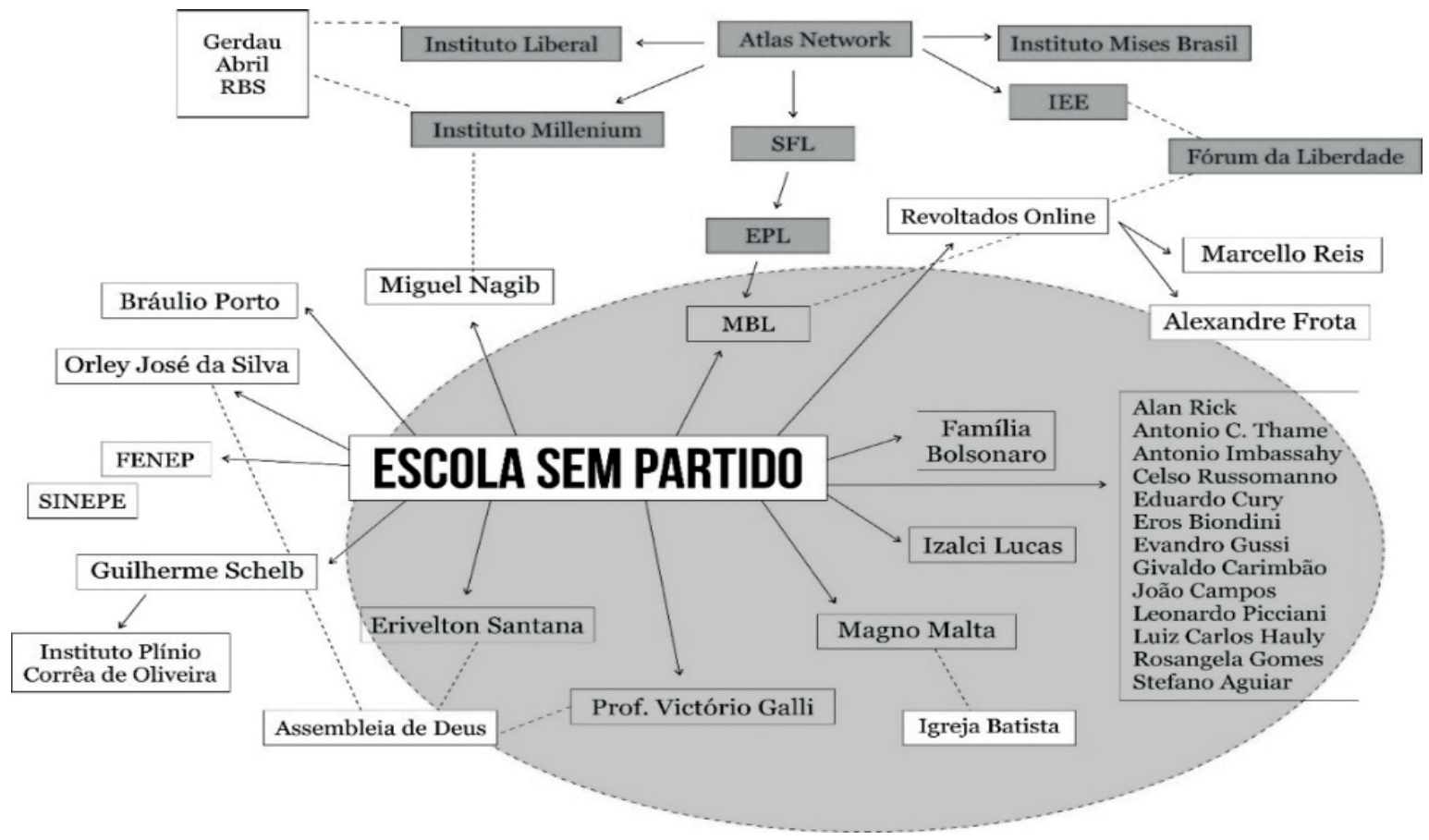


co de qualidade paratodos/as e que não reproduza mecanismos de diferenciação e de exclusão social,tais como classe, gênero, raça, sexo, identidade de gênero, orientação sexual,geração etc. (Rossi, 2016, p. 168)

Concordamos com Rossi e destacamos a posição de Peroni, Rossi, Pires, (2016) quando defendem que "as políticas de valorização da diversidade cumprem um importante papel na ampliação do próprio conceito de democracia, entendida como igualdade material, social, econômica, bem como o respeito às diferenças e valorização da diversidade" (p. 198). Enfim, destacamos as implicações para a democracia e a naturalização da censura vividas neste período em nosso país.

Lowy (2016) aponta que na história mundial, nos dois últimos séculos, a democracia é que foi excepcional, o que foi um peso para o Estado, para as classes dominantes e o capital financeiro. E conclui que, no Brasil, "mesmo democracia de baixa intensidade era intensa demais para as classes dominantes e o capital financeiro" (Lowy, 2016, p. 61).

Sobre a presença do mercado na educação, Rikowski (2017) ressalta que "a privatização na educação não é essencialmente sobre educação. Trata-se do desenvolvimento do capitalismo e do aprofundamento do domínio do capital em instituições específicas (escolas, faculdades, universidades etc.) na sociedade contemporânea." Para o autor: "As instituições de educação e de formação de professores estão envolvidas na produção social da força de trabalho (Rikowski, 1990). Assim, quando são privatizadas, as atividades, processos e formas pedagógicas envolvidas na produção de força de trabalho também são necessariamente privatizadas". (p. 395)

0 autor enfatiza, ainda, que existem duas formas básicas de privatização. A privatização direta, que refere-se à propriedade e trata da conversão da receita do Estado em lucro privado e a privatização na educação, que refere-se a formas de controle sobre a educação por parte das empresas. E ressalta que é importante a natureza da privatização, pois traz diferentes consequências. Sobre o capital disputando o fundo público o autor, aponta que:

(...) o financiamento estatal da educação aparece como uma fonte tentadora para sugar dinheiro público. 0 valor do mercado educacional mundial foi de \$ 4,9 trilhões (USD) em 2015 (Verger et al, 2017, p.325). 0 investimento em capital de risco em educação foi de quase US $\$ 2$ bilhões (USD) em 2014, mostrando um aumento de 45\% em 2009-2014 durante os anos da Grande Depressão (Ibid.). Nessas circunstâncias, a tomada de controle sobre a educação por parte das empresas não parece surpreendente, o que estimula a sua privatização. (RIKOWSKI, 2017, p. 398).

'Para o autor, a privatização da educação ocorre através da capitalização, quando o setor privado transforma a receita estatal em lucro"tornando-se capital. Trata-se do desenvolvimento capitalista na educação. (idem, p. 401)

0 autor adverte ainda que o lucro ocorre precarizando o trabalho docente: "a necessidade de apertar orçamentos e aumentar a carga horária dos professores torna-se uma necessidade pós-privatização, e a busca de outras medidas de redução de custos torna-se uma prioridade." Exatamente o que verificamos no documento do Banco Mundial "Um Ajuste Justo: Análise da eficiência e equidade do gasto público no Brasil". Conforme o documento, o poder público deve investir menos em educação: "uma análise de eficiência intermunicipal demostra que o desempenho atual dos serviços de educação poderia ser mantido com $37 \%$ menos recursos no Ensino Fundamental" (BANCO MUNDIAL, 2017, p.13). E aponta que o Estado gasta muito e mal : "As crescentes despesas públicas e a queda nos números de matrículas públicas resultam em um maior gasto por estudante e em razões aluno-professor ineficientes" (BANCO MUNDIAL, 2017, p. 121).

O Banco critica a vinculação de recursos, o que não por acaso entra na pauta atual:

Para municípios mais ricos a eficiência é ainda mais baixa dada a transição demográfica mais acelerada, o que resulta em uma redução mais rápida do número de alunos na rede pública. $\mathrm{A}$ obrigatoriedade constitucional de se gastar 25 por cento das receitas tributárias em educação 
contribui para que tais municípios aumentem os gastos por aluno de forma mais acelerada. Esse gasto adicional nem sempre se traduz em maior aprendizado, o gera ineficiências (BANCO MUNDIAL, 2017, p. 121).

0 documento responsabiliza os professores pela reprovação e baixa qualidade de ensino: "Além de uma razão aluno-professor relativamente baixa, o sistema público de educação no Brasil é caracterizado por baixa qualidade dos professores e pelos altos índices de reprovação. Todos esses fatores levam a ineficiências significativas (BANCO MUNDIAL, 2017, 121). Aponta ainda que os professores são mal formados, mal contratados, enfim, são os maiores culpados pelas ineficiências da educação:

O magistério permanece uma profissão desprestigiada. Os requisitos para ingresso em cursos de licenciatura são fracos e a formação é de baixa qualidade. É além da pouca seletividade na contratação de professores para os sistemas educacionais estaduais e municipais, os salários não se paradigma exigirá reformas coordenadas de políticas públicas nas esferas federal, estadual e municipal. As tendências demográficas, no entanto, oferecerão uma grande oportunidade para elevar o nível dos professores e da qualidade da educação ao longo da próxima década, pois estima-se que a população em idade escolar diminua em $25 \%$ entre 2010 e 2025 . Isso, aliado a um grande número de professores que irão se aposentar nos próximos anos, permitirá uma maior seleção na contratação de um número menor de professores que serão necessários para substituir os que estarão se aposentando (BANCO MUNDIAL, 2017, p.127)

Viviane Senna, presidente do Instituto Ayrton Senna, aponta nesta mesma direção, quando diz que os professores não sabem, por isso os conteúdos devem ser fortemente estruturados: "Os materiais são fortemente estruturados, de maneira a assegurar que mesmo um professor inexperiente, ou com preparação insuficiente - como é o caso de muitos professores no Brasil - seja capaz de pro-

porcionar ao aluno um programa de qualidade, com elevado grau de participação dos alunos na sala de aula, na escola e na comunidade". (SENNA, 2000, p. 146).

Enfatizamos que o diagnóstico de que o público vai mal e o privado deve ser o parâmetro de qualidade, expresso no documento do Banco Mundial e na fala presidente do IAS, que também participa de conselhos e do Movimento Todos pela Educação, sendo forte interlocutora do poder público, é parte do diagnóstico neoliberal, conforme apresentamos no início deste trabalho.

O diagnóstico que a educação pública vai mal e que o privado deve "contribuir" para elevar a qualidade, trazendo os princípios do mercado que são mais eficientes e produtivos.

É importante destacar que o Banco Mundial aponta para a diminuição de gastos em educação ao mesmo tempo em que fomenta a parceria com instituições privadas. Que oneram muito estados e municípios.

\section{ALGUMAS CONSIDERAÇÕES}

Com base nos conceitos do início do texto, de que o Estado, assim como o capital, é entendido como relação ou processo em um movimento de sujeitos em correlação de forças de classes sociais e projetos societários distintos, analisamos como a lógica mercantil e neoconservadora tem participado ativamente da direção e execução das políticas sociais. E como a presença desses sujeitos, que passam a influenciar fortemente as políticas sociais, deixa as responsabilidades ficarem cada vez mais diluídas quanto aos direitos materializados em políticas sociais.

Como apontamos no início do texto, direitos sociais materializados em políticas são parte do conceito de democracia. Mas, para que este direito se materialize, alguém deve ter o dever de assegurá-lo. Entendemos assim, que o Estado, enquanto poder público deve ser o responsável pelo direito. Neste sentido, analisamos criticamente as posições que repassam para a sociedade ou ao indivíduo a execução do que seriam seus direitos conquistados historicamente. 
Destacamos as consequências para um projeto societário e de educação do individualismo e não mais o coletivismo como paradigma. Ao longo do texto verificamos que o foco no individualismo foi capaz de unir conservadores e libertários no neoconservadorismo e destacamos que o individualismo é uma posição comum, também ao neoliberalismo e à terceira via. Harvey (2008), ao tratar da neoliberalização, que é o balanço da teoria neoliberal na prática, destaca que o mercado regula o bem-estar humano e a competição é o seu mecanismo regulador. Por conseguinte, o sucesso e o fracasso são considerados individuais por meio das virtudes empreendedoras do indivíduo: "O sucesso e o fracasso individuais são interpretados em termos de virtudes empreendedoras ou de falhas pessoais (como não investir o suficiente em seu próprio capital humano por meio da educação), em vez de atribuídos a alguma propriedade sistêmica (como as exclusões de classe que se costumam atribuir ao capitalismo) (HARVEY, 2008, p. 76).

É importante ressaltar a especificidade brasileira, pois os avanços das lutas por direitos sociais ocorreram no momento pós-ditadura, na década de 1980, mesmo período de crise capital (Mészáros, 2002, Harvey, 1989). Período em que o capitalismo propunha um conjunto de estratégias para retomar o aumento das taxas de lucro, reduzindo direitos, com graves consequências para a construção da democracia e da efetivação dos direitos sociais, materializados em políticas públicas, dando lugar ao que temos chamado de "naturalização do possível" (Peroni, 2013). 


\section{REFERÊNCIAS}

ADRIÃO Theresa - Dimensões e formas da privatização da educação no Brasil: caracterização a partir de mapeamento de produções nacionais e internacionais. Currículo sem Fronteiras, v. 18, n. 1, p. 8-28, jan./abr. 2018.

ADRIÃO, Theresa; PERONI, Vera. Análise das consequências de parceria firmadas entre municípios brasileiros e a Fundação Ayrton Senna para a oferta educacional. Relatório de Pesquisa, 2011. Disponível em:http://www.ufrgs.br/faced/peroni/docs/ INSTITUTO\%20AYRTON\%20SENNA\%20RELATORIO.pdf.

ADRIÃO, Theresa, GARCIA Teise de Oliveira Guaranha. Educação a domicílio: o mercado bate à sua porta. Revista Retratos da Escola, Brasília, v. 11, n. 21, p. 393-413, jul./dez. 2017 ADRIÃO, Theresa, DOMICIANO, Cassia Alessandra. A Educação Pública e as Corporações: avanços e contradições em uma década de ampliação de investimento no Brasil. FINEDUCA, Revista de Financiamento da Educação, Porto Alegre, v. 8, n. 3, 2018.

AMARAL. Marina. A nova roupa da direita. A publica jornalismo investigativo. 23/6/2015. Disponível em: $<$ https://apublica.org/2015/06/a-nova-roupa-da-direita/>. Acesso em: 20 jun. 2018.

BANCO MUNDIAL. Um Ajuste Justo: Análise da eficiência e equidade do gasto público no Brasil, 2017.

BERNARDI, Liane Maria; UCZAK, Lucia Hugo; ROSSI, Alexandre José. RELAÇÕES DO MOVIMENTO EMPRESARIAL NA POLÍTICA EDUCACIONAL BRASILEIRA: a discussão da Base Nacional Comum. Currículo Sem Fronteiras, Porto Alegre, v. 18, n. 1, p.2951, 2018. Quadrimestral.

BEZERRA Vinícius, BUSATO, Carla. A reforma do ensino médio: privatização da política educacional, Revista Retratos da Escola, Brasília, v. 11, n. 21, p. 393-413, jul./dez. 2017.

LOWY.Michael. Da tragédia à farsa: o golpe de 2016 no Brasil. In: JINKINGS. Ivana, KLIN. Doria; CLETO. Murilo. Porque gritamos Golpe. Para entender o impeachment e a crise política no Brasil. São Paulo:Boitempo Editorial, 2016. LIMA, Paula Valim. Escola sem sentido: Implicações da Escola sem Partido para a democratização da educação pública. Graduação em Educação, Faculdade de Educação, Universidade Federal do Rio Grande do Sul, Porto Alegre, 2017.

MÉSZÁROS, István. Para além do Capital. São Paulo: Boitempo Editorial; Campinas: Editora da UNICAMP, 2002.

MOLL NETO NETO, Roberto. Reaganation: a nação e o nacionalismo (neo) conservador nos Estados Unidos (1981-1988).
Dissertação (Mestrado em História) - Programa de Pós-Graduação em História, Universidade Federal Fluminense, 2010.

PERONI Vera Maria Vidal, LIMA Paula Valim de e KADER, Carolina Rosa (org.) Redefinições das fronteiras entre o público e o privado: implicações para a democratização da educação São Leopoldo: Oikos, 2018.

PERONI, Vera (Org.). Redefinições das fronteiras entre o público e o privado: implicações para a democratização da educação. Brasília: Liber Livro, 2013.

PERONI, Vera (Org.). Diálogos sobre as redefinições no papel do Estado e nas fronteiras entre o público e o privado na educação. São Leopoldo: Oikos, 2015.

PERONI, V. M. V.; CAETANO, M. R. 0 público e o privado na educação Projetos em disputa?. Retratos da Escola, v. 9, p. 337 352,2015

PERONI, Vera, CAETANO, Maria Raquel, LIMA Paula Valim. Reformas educacionais de hoje: as implicações para a democracia. Revista Retratos da Escola, Brasília, v. 11, n. 21, p. 393 413, jul./dez. 2017.

PERONI, Vera, PIRES, Daniela, ROSSI, Alexandre.Os desafios da Construção das politicas de diversidade no processo de democratização In: VII ENCUENTRO INTERNACIONAL DE INVESTIGADORES DE POLITICAS EDUCATIVAS. 1 ed.Montevideo :Universidad de la Republica, 2016, p. 191-198.

RIKOWSKI, Glenn. Privatização em educação e formas de mercadoria, Revista Retratos da Escola, Brasília, v. 11, n. 21, p. 393-413, jul./dez. 2017

ROCHA, Camila. O papel dos thinktanks pró-mercado na difusão do neoliberalismo no Brasil. MILLCAYAC - Revista Digital de CienciasSociales / Vol. IV / Nº 7 / 2017. ISSN: 2362-616x. (pp. 95-120) Centro de Publicaciones. FCPyS. UNCuyo. Mendoza.

ROSSI, Alexandre José. As políticas de diversidade na educação: uma análise dos documentos finais das CONAEs, DCNs e PNE. 2016. 176 f. Tese (Doutorado) - Curso de Educação, Universidade Federal do Rio Grande do Sul, Porto Alegre, 2016.

VIEIRA. Evaldo. O Estado e a sociedade civil perante o ECA e a LOAS. Serviço Social \& Sociedade, São Paulo: Cortez Editora, n. 56, p. 9-23, mar. 1998.

WOOD, Ellen. Democracia contra o capitalismo a renovação do materialismo histórico. São Paulo: Boitempo Editorial, 2003. 